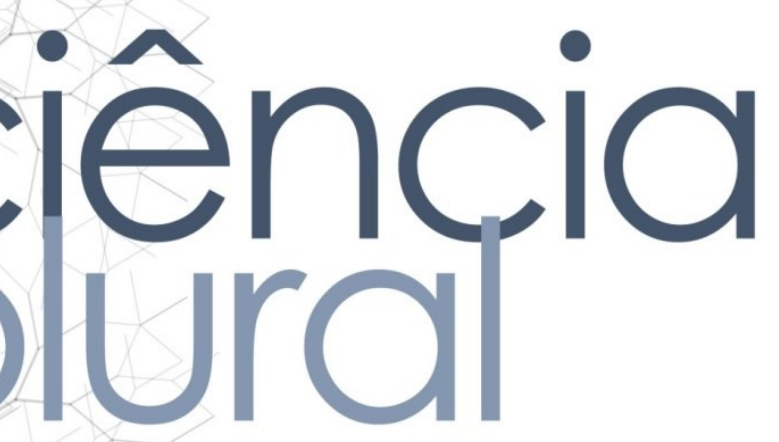

\title{
AUTO-ORGANIZAÇÃO E AUTONOMIA: PRINCÍPIOS BÁSICOS NA CARACTERIZAÇÃO DE SAÚDE MENTAL
}

Self-organization and autonomy: basic principles in the characterization of mental health

Daniel Luporini de Faria • Mestre em Filosofia da Mente, Lógica e Epistemologia pela Universidade Estadual Paulista “Júlio de Mesquita Filho" (UNESP-Marília).E-mail: luporinifaria@yahoo.com

Autor responsável pela correspondência:

Daniel Luporini de Faria. Mestre em Filosofia da Mente, Lógica e Epistemologia pela Universidade Estadual Paulista "Júlio de Mesquita Filho" (UNESP-Marília). Rua Manoel Queirós, 77, Jardim São Pedro, Jaguariúna-SP, CEP 13820-000. Tel. (19) 3867 2743. E-mail: luporinifaria@yahoo.com 


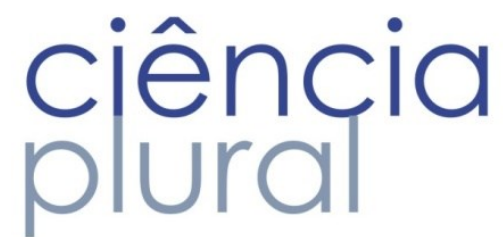

RESUMO

Introdução: Se na tradição ocidental vigora a abordagem mecanicista, de inspiração cartesiana, onde a doença é isolada analiticamente e tratada, na tradição oriental a relação saúde-doença é, há milênios, concebida como uma desarmonia biopsicossocial de um indivíduo inserido num meio e dotado de rica subjetividade. Em documento de 2001, a Organização Mundial de Saúde faz menção a uma abordagem médica sistêmica, integrada, tal qual os chineses praticam há muito tempo. Pensando nessa mudança de paradigma, entendemos haver, em nossa cultura, certa carência de ferramentas epistemológicas capazes de lidar com essa complexidade. Objetivo: Contrapor as perspectivas orientais (chinesa, em particular) no trato com a saúde (a mental, em específico), com a tradição ocidental de práticas médicas. Método: Estudo de abordagem qualitativa mediante revisão bibliográfica e análise interpretativa, estabelecendo-se comparação entre os dois tipos de prática médicas. Resultados: Nesse sentido, foram explorados os princípios da teoria da auto-organização, sugerindo que tal abordagem epistemológica poderia ser de extrema valia no que concerne à elaboração de um novo olhar sobre as relações médico/paciente e saúde/doença.

Palavras-Chave: Processo saúde-doença; autonomia pessoal; saúde mental.

\section{ABSTRACT}

Introduction: If in the Western tradition the Cartesian-inspired mechanistic approach, where disease is analytically isolated and treated, in the Eastern tradition the health-disease relationship has been conceived for millennia as a biopsychosocial disharmony of an individual inserted in a medium and gifted of rich subjectivity. In a 2001 document, the World Health Organization mentions a systemic, integrated medical approach, as the Chinese have long practiced. Thinking of this paradigm shift, we understand that there is in our culture a certain lack of epistemological tools capable of dealing with this complexity. Objective: To oppose the Eastern (Chinese, in particular) perspectives of treatment with health (the mental, in particular), with the Western tradition of medical practices. Methodology: Study of qualitative approach through bibliographic review and interpretative analysis, establishing a comparison between the two types of medical practice. Results: In this sense, the principles of the theory of self-organization were explored, suggesting that such an epistemological approach could be of extreme value in the elaboration of a new look on the doctor / patient and health / illness relationships.

Key words: Health-disease process; personal autonomy; mental health. 


\section{ciência plural}

\section{Introdução}

Além da ausência de enfermidade, "saúde", de acordo com a Organização Mundial da Saúde (OMS), em documento divulgado em 2001, seria também o estado de completo bem estar físico, mental e social1. De tal definição de saúde, pensada enquanto antônimo de doença, pressupõe-se a inseparabilidade de fatores físico-biológicos, psíquicos e sociais, que seriam concebidos como aspectos da vivência estreitamente relacionados e interdependentes. Ainda segundo o documento da OMS, a ideia de "saúde mental" abrangeria o bem estar subjetivo, a autonomia, a competência, a dependência intergeracional e a autorrealização do potencial intelectual e emocional do indivíduo¹.

Para a OMS, a rigor, o indivíduo doente deve ser entendido enquanto uma unidade biopsicossocial, o que talvez dê ensejo para se pensar em novas estruturas epistemológicas que se coloquem enquanto alternativas à prática médica de nossa tradição ocidental, que se embasa no procedimento de "análise", cartesianamente, dividindo o organismo em partes, isolando e tratando as partes doentes ou comprometidas.

Essa mudança de paradigma, expressa nas entrelinhas no referido documento da OMS, estimula a imaginação no sentido de pensar novos recursos epistemológicos que sirvam melhor à prática médica em geral, e ao cuidado em saúde mental em particular. Nesse sentido, pensar novas formas de cuidado em saúde mental, adequadas ao pressuposto de organicidade biopsicossocial, é o objetivo do presente trabalho, que se propõe a avaliar algumas noções da teoria da auto-organização, a fim de que se ressalte a importância da compreensão de como as esferas físico-biológicas se relacionam com as esferas mentais e sociais.

\section{Dividir, isolar e tratar}

$\mathrm{Na}$ antiguidade clássica, os mitos de Hygéia (deusa da saúde) e Asclépius (deus da medicina) representavam dois aspectos basilares da medicina. Aos adeptos de Hygéia, a saúde dependia fundamentalmente do modo como se orientava a vida cotidianamente. Com isso, cabia ao médico investigar como um indivíduo qualquer deveria organizar suas relações sociais, compatibilizando-as ao seu próprio físico por meio de restrições comportamentais e alimentares, dado que a cura para uma enfermidade viria sempre da natureza, e a enfermidade de um relacionamento disfuncional com ela. A doença, nesta perspectiva, decorreria de uma assimetria, de um relacionamento social desarmônico.

Os seguidores de Asclépius, por sua vez, pensavam que a função do médico seria essencialmente a de tratar a doença, corrigindo as imperfeições oriundas da vida por meio de terapias mais incisivas, sem a preocupação em determinar um dado estilo de vida ao doente. A ênfase era dada, portanto, nas questões sintomáticas e curativas/paliativas da medicina. 


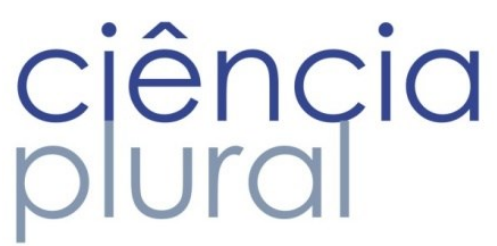

A medicina desenvolvida por Hipócrates, grosso modo, nada mais foi que uma espécie de síntese elaborada a partir dessas duas tendências, dado que ela debruça-se tanto sobre a própria doença individual, bem como sobre os meios para extirpá-la, preocupando-se também com a manutenção da saúde dentro de um esquematismo ecológico de equilibrio com o meio ambiente.

Durante a Idade Média, a medicina manteve como primado as concepções aristotélicas, desenvolvimento da medicina hipocrática, frisando a comunhão orgânica dos seres vivos e entendendo 0 adoecimento como expressão de variações globais do organismo em permanentes trocas recíprocas com 0 meio físico-biológico e social. Deste modo, subentendia-se que do mesmo modo como os humores e líquidos do organismo influenciam as virtudes do homem, reciprocamente, as virtudes influenciariam os humores.

A partir deste breve preâmbulo um tanto geral, do desenvolvimento da medicina na antiguidade e medievo, agora já no século XVII, Descartes ${ }^{2,3}$ estabeleceu os princípios e métodos para se conceber 0 corpo humano como uma maquinaria. Assim como Galileu tinha mostrado que o método cientifico era capaz de providenciar uma interpretação mecânica do mundo físico, Descartes não via razão para que os mesmos princípios não fossem estendidos ao mundo dos seres biológicos. Criando a dicotomia assimétrica entre mente ou espírito (alma), que seria caracterizada pelo livre arbítrio de uma substância imaterial essencialmente pensante e indivisível, unida inextricavelmente (como um timoneiro e seu navio, com um corpo físico, divisivel e regido pelas leis da mecânica). Nesse esquematismo cartesiano, onde a doença se coloca enquanto uma anomalia de um dos componentes da máquina humana, passível de ser "corrigido" mediante intervenção de um profissional que gozasse do conhecimento das leis que operam essa máquina, o corpo ou máquina humana perdia seu caráter divino, sagrado (bem conhecidas são as experimentações de Descartes com animais, especialmente cachorros, que eram dissecados ainda vivos pelo filósofo, que considerava seus urros e gemidos como meros automatismos, já que, para Descartes, o sentimento só existiria em seres dotados de alma, algo que ele não reconhecia como presente nos animais e em seres humanos possuidores de enfermidades mentais ou "idiotas" [idiof], como ele se referia a tais pessoas, mas apenas nos seres humanos "normais").

Essa maneira de se pensar medicina e a prática médica, dividindo, isolando e tratando unicamente a doença das partes comprometidas (inspirada no mito grego de Asclépius), como se o organismo fosse uma máquina, pode-se dizer, vigorou até os dias correntes, sendo a filosofia de Descartes o embasamento teórico de tal visão de mundo e saúde.

\section{A virada orientalista (chinesa)}

Na medicina tradicional chinesa (中醫, zhōngyī xué, ou 中藥學, zhōngyaò xué), praticada desde tempos imemoriais, a perfeita saúde é concebida como um processo resultante de um perfeito equilíbrio de forças (Yin e Yang) em permanente desenvolvimento, que se equilibra mediante um jogo de forças contrárias 


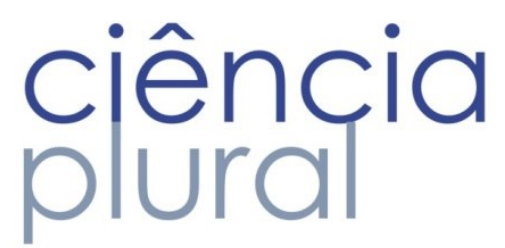

e complementares. Presumimos, com base nos estudos de respeitáveis historiadores da filosofia, em especial Mondolfo 4 e Koiré 5 que, dada a marcante influência do pensamento oriental na gênese e primeiros desenvolvimentos da filosofia grega, o mito de Hygéia teria por base e inspiração no pensamento chinês, para o qual a perfeita saúde seria decorrente da harmonização entre corpo e mente, entre práticas sociais e físico-alimentares combinadas a exercícios físicos e comunhão salutar entre organismo e meio ambiente, que comporiam a equação da qual deriva a perfeita saúde ou harmonia do corpo com o espírito e ambiente.

Vemos como uma espécie de resgate, por parte do ocidente, dos anos 60 do século XX para cá, dessas práticas médicas e filosóficas orientais. A acupuntura, por exemplo, já se constitui em prática frequente de médicos ocidentais no que diz respeito a uma melhora da condição de vida de seus pacientes. Em ciência, educação e filosofia, a interdisciplinaridade nos currículos das universidades ocidentais é cada vez mais incentivada, o que denuncia que a comunhão entre os saberes, a organicidade de conhecimentos, caminham, cada vez mais, para a valorização de uma visão sistêmica do real. A teoria da auto-organização é só mais um exemplo desse processo que tem se acentuado cada vez mais desde os anos 60 do século $X X$.

\section{Teoria da auto-organização}

A palavra "auto-organização" aparece pela primeira vez (no contexto do movimento cibernético) em um artigo do psiquiatra W. Ross Ashby, em 19476. Herdada da "Teoria Geral de Sistemas", de Bertalanffy6, pergunta-se Ashby em seu referido artigo: como seria possível um sistema determinista mudar espontaneamente sua organização interna? Argumenta Ashby que basta que algumas das variáveis que determinem o sistema, por exemplo, $\mathrm{x}$, seja inobservável. Assim, o sistema parecerá se comportar de forma espontânea, quando na verdade ele não se comporta. No caso do sistema nervoso humano, atribuímos a ele uma dinâmica auto-organizada em virtude de não conhecermos todas as variáveis do sistema nervoso com acuidade?

Tal leitura do termo auto-organização feita por Ashby remete inevitavelmente à clássica inquietação metafísica de se o universo é determinista ou "tiquista", ou melhor, se no processo de desenvolvimento do Ser surgem novidades genuínas, ou se tudo é pré-determinado, com a organização das condições iniciais e primeiros desenvolvimentos determinando rigorosamente todos os estados posteriores. Por aqui, não entraremos nessa complexa questão, limitar-nos-emos, apenas, em colocar que as intuições de Ashby de que o desconhecimento das minúcias de um dado sistema é que nos leva a atribuir a noção de autoorganização a este sistema.

Essa leitura da auto-organização feita por Ashby, evidentemente, tem como pressuposto um universo fundamentalmente determinista, onde as "novidades" da natureza seriam apenas aparentes, resultantes do desconhecimento do investigador. Mas essa não é a única leitura da ideia de auto-organização. Inspirado 


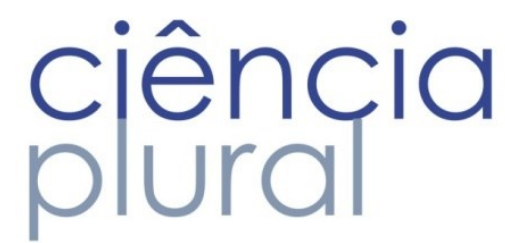

na obra do matemático e economista francês Antoine Augustin Cournot $^{8}$, Michel Debrun ${ }^{9,10}$, por exemplo, entende que a ideia de acaso seria de fundamental importância. Contrariando a perspectiva de um universo determinista, Debrun entende, resumidamente, que a congruência de inúmeros fatores independentes possibilitaria a emergência do novo, de modo que a noção de acaso seria central em suas ideias. $O$ universo de Debrun seria um universo indeterminista, ao passo que o de Ashby seria determinista. No presente artigo, optamos por explorar uma ideia de auto-organização situada num universo "tiquista" ou indeterminista, sendo Debrun a referência teórica escolhida.

Nos estudos em auto-organização, em especial, na teoria da auto-organização tal qual propõe Michel Debrun9,10, haveria, pelo menos, duas fases na constituição de um sistema auto-organizado: a) Autoorganização primária: que ocorreria quando um novo sistema se forma a partir do encontro casual de elementos que pertenciam a outros sistemas; b) Auto-organização secundária: que ocorreria em um sistema já constituído, quando um novo padrão de organização se constituiria a partir das interações entre seus componentes e com o ambiente.

Os princípios-chave da teoria da auto-organização em Debrun seriam: (i) a partir da interação entre as partes se gera uma forma global nova no sistema; (ii) com o decorrer do processo ocorreriam ajustes das e entre as partes do sistema; (iii) a auto-organização nunca é absoluta, pois ela coexiste com a heteroorganização, podendo derivar do controle centralizado de um agente interno ao sistema.

Uma questão interessante seria: o que, exatamente, torna um dado sistema em um sistema autoorganizado? Relacionando o conceito de auto-organização às definições de "ordem" e "entropia" da termodinâmica, Heinz von Foerster ${ }^{11}$, numa palestra de 1959, publicada em livro de 1960, responde que não há algo como um sistema auto-organizado, porque estar-se-ia pensando em sistemas isolados, e, até onde se sabe, de acordo com a segunda lei da termodinâmica, em tais sistemas a entropia e a desordem aumenta até um valor máximo. Como ele está pensando no grau de "ordem" do sistema, podemos redefinir sua tese dizendo que não há sistemas isolados auto-organizados. Auto-organização só existiria em sistemas abertos. Citando a terminologia de Erwin Schrödinger ${ }^{12}$, sistemas abertos, como os seres vivos, se "alimentariam" de entropia negativa proveniente do ambiente.

Uma segunda questão importante de Von Foerster seria: quanta ordem um sistema pode assimilar de seu ambiente? Em resposta, argumenta Foerster primeiramente que existe, na realidade, um ambiente e, em seguida, que este ambiente possui "estrutura", ou seja, possui ordem, já que a entropia do universo ainda não é máxima. Em seguida, salienta que a definição de "sistema" pode não ser muito clara, quando não houver uma membrana separando o sistema de seu ambiente. Se quisermos justificar o uso do prefixo "auto", cremos ser difícil definir o que é "dentro" do sistema. 


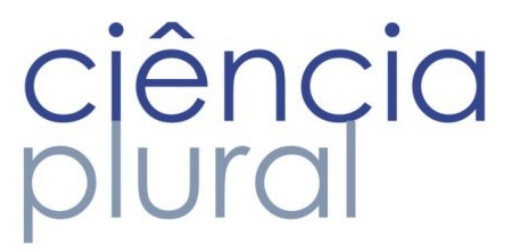

Mas independentemente das dificuldades de se isolar um sistema, podemos resumir autoorganização enquanto um processo que, segundo Pereira Júnior e Pereira ${ }^{13}$, caracteriza-se por:

A. Ser espontâneo;

B. Com respostas construtivas às perturbações, onde "os sistemas auto-organizados são complexos semiabertos (ou semifechados), que derivam seus padrões de organização das relações internas entre seus componentes. Perturbações de origem externa podem ser utilizadas construtivamente, deflagrando processos organizacionais"13;

C. Com presença de causalidade circular, travando relações de feedback entre si, tal qual o conceito de autopoiese, elaborado por Maturana e Varela ${ }^{14}$, inspirado no funcionamento celular, sendo que este conceito diria respeito a uma causalidade circular de genoma e metabolismo, com os genes instruindo a produção das proteínas, que regulam o metabolismo, de modo que os produtos deste, por sua vez, regulariam a expressão dos genes. $E$, finalmente;

D. Não linearidade, em que os sistemas auto-organizados apresentariam aspectos de não linearidade, que seria a desproporção entre magnitude de causas e efeitos no sistema (efeito borboleta).

Inspirados em Aristóteles ${ }^{15}$, entendemos que o Ser seria um manancial com possibilidades infinitas de atualizações, sendo a florada de uma mangueira, por exemplo, tão somente a ocasião de atualização de uma potencialidade que já estava presente na própria semente que originou essa mangueira. Contudo, salientamos também que trabalharemos com um modelo de universo tiquista, inspirado em Cournot, onde a "novidade" seria um fato da natureza. Uma questão interessante e altamente destrutiva se dirigida à este modesto artigo seria a de que se na medida em que pensamos ser 0 universo indeterminista, tendo emergência de novidades genuínas nele, como poderiam estar inscritas na natureza todas as potencialidades desse universo? Essa é uma boa possibilidade de crítica.

Em resposta, podemos dizer que, assim como na linguagem temos um alfabeto finito com combinações potencialmente infinitas, na natureza, também se observa um processo no qual as combinações das potencialidades (entendidas como independentes umas das outras) possibilitam um processo "courtnotiano" ou "debruniano" não determinista, com emergência de novidades no sentido forte. Essa ideia de emergência combinatorial não estaria em Aristóteles, mas pode ser encontrada em Chomsky ${ }^{16}$, por exemplo. E o aspecto indeterminista viria da teoria de sistemas complexos, como por exemplo, no conjunto dos trabalhos do filósofo e lógico brasileiro Newton da Costa, para o qual as interações dos elementos da natureza gerariam uma dinâmica caótica imprevisível. Isso porque cada linha causal seria determinista, mas as linhas seriam independentes, de modo que quando elas se cruzam, o resultado seria imprevisível ou não calculável. 


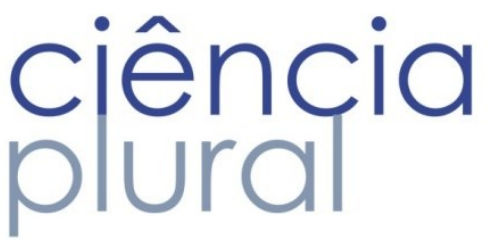

\section{Articulação de esferas do real}

Como as próprias caracterizações de saúde e saúde mental da OMS sugerem, cada indivíduo constitui-se numa unidade biopsicossocial, onde o desequilíbrio de uma das esferas afeta todo o sistema, desencadeando a doença (coisa que na tradição oriental é lugar comum há milênios). As neurociências e psicologia contemporâneas sugerem que, assim como em inúmeras doenças orgânicas, os transtornos mentais resultam de uma complexa miríade de fatores, sendo que o desvelamento das interações entre os sistemas nervoso, imune e endócrino têm acarretado na instauração de novas áreas interdisciplinares que se debruçam sobre a relação mente-corpo, especialmente, a psicossomática, que parte do princípio de que haveria uma mútua influência da saúde física na saúde mental e vice-versa.

Além disso, transtornos mentais dependem fortemente de fatores psicossociais (além de físicos e genéticos, é claro). Pois desde a mais tenra infância, as relações com os pais são de extrema importância para a estruturação mental do indivíduo, bem como quando adulto: "certos fatores sociais como a urbanização desmedida, a pobreza, a competição profissional e rápida absorção de novas tecnologias, entre outros, trazem implicações para a saúde mental"17.

Partimos dos pressupostos de uma metafísica monista, que entende o Ser enquanto unidade. De acordo com essa cosmovisão, o desenvolvimento do Ser obedece a uma lógica em que os domínios físico, biológico, psíquico e social seriam atualizações, na natureza, de um único Ser infinito em potencialidades, e que comporiam uma unidade, mesmo que, epistemologicamente, possam ser atribuídas dinâmicas interpretativas próprias a cada domínio da natureza. Mesmo que não se saiba ainda exatamente como as esferas da natureza se correlacionam, partimos da intuição de Bertalanffy ${ }^{6}$ de que os isomorfismos existentes na natureza são inteiramente reais, de modo que estabelecer princípios e leis integrados entre as diversas esferas do real não só é possível, como também desejável (daí a importância que entendemos haver em estudos interdisciplinares).

Uma ferramenta útil ao entendimento das relações entre os diferentes níveis da realidade, em especial, no que diz respeito à própria constituição dos indivíduos e emergência da autonomia de tais indivíduos, talvez possa ser encontrada nos princípios básicos da Teoria da Auto-Organização (TAO), tal qual resumimos e problematizamos na seção anterior.

\section{Metodologia}

Por tratar-se de uma abordagem qualitativa, este artigo concentra-se no levantamento e reflexão crítica acerca da bibliografia concernente à temática, visando uma melhor compreensão e reflexão sobre as questões colocadas. Segundo Turato ${ }^{18}$, expressando opinião com a qual concordamos, a metodologia 


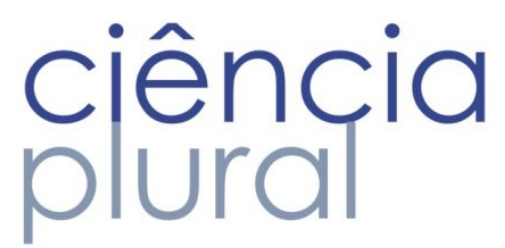

qualitativa deve ser aplicada quando o objetivo da pesquisa é a compreensão do significado dos fenômenos. Para o referido autor, e para nós, no contexto da metodologia qualitativa aplicada à saúde, emprega-se a concepção trazida das ciências humanas, segundo a qual não se busca estudar o fenômeno em si, mas entender seu significado individual ou coletivo para a vida das pessoas. Assim, os indivíduos organizarão, de certo modo, suas próprias vidas, incluindo seus próprios cuidados com a saúde. Ademais, pensamos, na esteira de Rosana Teresa Onocko-Campos ${ }^{19,20}$, que estudos qualitativos em saúde mental são de vital importância no que tange ao entendimento e ação efetiva de políticas públicas no que se refere ao empoderamento dos usuários de saúde mental.

\section{Auto-organização e autonomia: princípios básicos na caracterização de saúde mental}

Como aventamos, cada indivíduo constitui-se numa unidade biopsicossocial, sendo que um modo interessante de se conceber a saúde de cada indivíduo seria pensá-la enquanto a perfeita harmonia entre essas esferas. No caso da harmonia mental, como dissemos, e como a própria OMS reconhece, a autonomia seria de vital importância. Como argumenta Saraceno ${ }^{21}$, a reabilitação psicossocial de uma pessoa doente mentalmente conteria elementos de auto-organização, tal qual delineada na seção anterior, na medida em que uma perturbação de ordem social, por exemplo, abalaria todo o sistema, gerando desequilíbrio e, consequentemente, a doença. Além disso, devemos acrescentar que a terapia adequada deve salientar a importância do próprio paciente na elaboração mental do processo terapêutico, o que seria uma perspectiva ativa, que fortalece a autonomia, organizada em primeira pessoa, e que se contraporia à perspectiva de terceira pessoa, onde os profissionais de saúde que determinariam "de cima para baixo" todo o processo terapêutico.

Saraceno ${ }^{21}$, em suas análises sobre os fatores sociais nas enfermidades mentais, confere especial ênfase ao ambiente social no qual o paciente está imerso, o que constitui grande avanço, porém, não formula uma visão sistêmica da organicidade biopsicossocial, fundamentada no sujeito da experiência. Essa leitura também é feita por Lussi, Pereira e Pereira Júnior ${ }^{22}$, os quais acrescentam que ao domínio médico, a principal contribuição da teoria da auto-organização seria o entendimento da pluralidade de fatores que, quando compreendidos e alterados pela ação consciente do paciente, fomentariam o processo de edificação da harmonia e desconstrução da desarmonia.

No Brasil, desde o final da década de 70 do século XX, começa a se verificar um movimento no sentido de resgate de cidadania dos chamados "loucos" por meio de movimentos sociais que se articularam no bojo das mudanças políticas que ocorreram no Brasil ao final do regime militar ${ }^{23}$. O movimento que ficou 


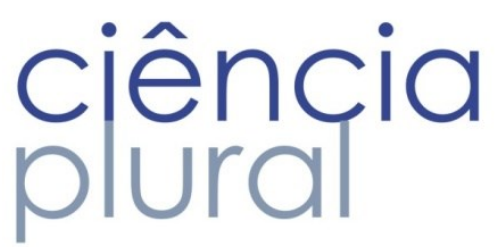

conhecido como "luta antimanicomial", tem na sua origem, no Brasil, a reforma sanitária brasileira, da qual resultou a criação do sistema único de saúde (SUS) e que está ligada à experiência de desinstitucionalização da psiquiatria desenvolvida na Itália por Franco Basaglia, nos anos 60. Como processo decorrente deste movimento, no Brasil, a reforma psiquiátrica, definida pela lei: 10216 de 2001 (lei Paulo Delgado) transfere o foco do tratamento aos doentes mentais, que se concentrava em instituições hospitalares, para Hospitais Dia e Centros de Atenção Psicossocial (CAPS), que seriam espaços de convívio e tratamento estruturados em unidades de serviços comunitários e abertos, onde a autonomia dos pacientes seria amplamente preservada e desenvolvida, na medida em que, pelo menos nos CAPS bem estruturados, os pacientes têm a liberdade de escolher suas atividades e teriam um papel muito mais ativo no processo terapêutico que nos antigos manicômios. Em resumo, o valor atribuído à reforma psiquiátrica seria 0 de um movimento, um processo histórico que se constitui pela crítica ao paradigma médico-psiquiátrico e pelas práticas que transformam e superam esse paradigma24. Embora com particularidades regionais significativas, no amplo espaço geográfico nacional, "como processo histórico, insere-se numa totalidade complexa e dinâmica, determinada pelos processos sociais, regionais e nacionais, a partir dos anos 80 até a atualidade"25.

O conceito de autonomia é um dos princípios da Bioética, campo de estudo e experiências que se propõe a romper com concepções paternalistas na medicina, onde os profissionais de saúde detinham todo o poder decisório, determinando o tratamento a ser realizado pelo paciente de "cima para baixo". Com isso, o cultivo e aprofundamento da autonomia pode subverter essa lógica paternalista.

Edgar Morin26, por exemplo, argumenta que a autonomia é um conceito estreitamente ligado à noção de dependência, sendo a noção de dependência estritamente relacionada ao conceito de auto-organização. Entende que autonomia implica na ideia de dependência com o mundo externo, já que a auto-organização depende, como vimos, do ambiente, seja ele biológico, sociológico ou cultural. Pensando deste modo, depreende-se que auto-organização significa, acima de tudo, autonomia, tendo em mente que o indivíduo autônomo depende necessariamente do mundo exterior, energeticamente, informativa e organizacionalmente, na medida em que um sistema auto-organizado deve trabalhar para a construção e reconstrução de sua própria autonomia o tempo todo.

Canguilhen ${ }^{27}$, por exemplo, pensando na questão da autonomia do indivíduo doente, se aproxima da noção de autonomia de Morin26, ao entender que o organismo vivo seria dotado de uma potência autorreparadora. Nesta perspectiva, as noções de "normal" e "patológico" seriam afirmadas, sobretudo, enquanto valores, onde seria a normatividade e não a cientificidade que estabeleceria a distinção entre tais noções. 


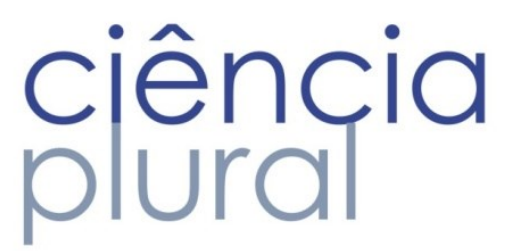

Kynoshita ${ }^{28}$, seguindo a mesma linha de raciocínio, concebe o conceito de autonomia como sendo a capacidade do indivíduo em gerar normas para a própria existência mediante ampliação de suas relações sociais. Com isso, o estabelecimento e ampliação de contratos sociais possibilitariam ao indivíduo gerar novas normas para contextos diversos. Assim, a noção de autonomia é ampliada para além de antônimo de dependência ou sinônimo de liberdade absoluta. Autonomia, por assim dizer, passa a ser entendida como a capacidade do sujeito em lidar com suas redes de dependências.

Com base em tais pressupostos, Soares e Camargo Júnior ${ }^{29}$, explorando uma concepção complexa de autonomia, recomendam a superação das relações autoritárias e paternalistas no processo saúdedoença por meio do estreitamento das relações entre pacientes e profissionais de saúde, entre pacientes e familiares, o que fomentaria, assim, a formação de redes de autonomia-dependência, essenciais no que concerne ao estabelecimento do cuidado-atenção e da saúde, propiciando a tessitura permanente da autonomia, na medida em que se desenrola o processo terapêutico.

Pensar a ampliação e aprofundamento da autonomia como um dos objetivos do trabalho em saúde implica, necessariamente, na redefinição de valores políticos e de conceitos que orientam tal trabalho em saúde, de modo que a principal alteração deve ser a redefinição do próprio objeto do trabalho em saúde, que deve centrar-se no sujeito com desarmonia, sujeito este, fundamentalmente, dotado de subjetividade e particularidades ${ }^{30}$.

Enfocamos a atenção no sujeito-paciente, e entenda-se isso como uma espécie de revolução, na medida em que ao longo da história da medicina moderna, o objeto de intervenção médica tem sido a doença, o que fomenta a construção de uma concepção reducionista do processo saúde-doença. A medicina tradicional, cartesianamente, ao estilo da ciência mecanicista dos séculos XVII e XVIII, apropria-se de concepções baseadas na neutralidade e objetividade, debruçando-se unicamente na doença, nos órgãos e tecidos comprometidos, pequenas partes e sintomas, negligenciando as dimensões socioculturais envolvidas no processo de adoecimento, ocasionando um distanciamento na relação com o paciente, e deste com seu próprio corpo.

Entendemos que a autonomia é um valor necessário à assistência médica e psicológica, necessitando ser resgatada nas práticas clínicas, nas ciências sociais, humanas e de saúde ${ }^{29}$. Assim, todo e qualquer processo terapêutico deveria ter como princípio a construção contínua e o fortalecimento da autonomia do indivíduo envolvido no processo saúde-doença, principalmente, quando esta se encontra limitada pelo adoecimento. Deste modo, o movimento da reforma psiquiátrica apresenta novas possibilidades de se 


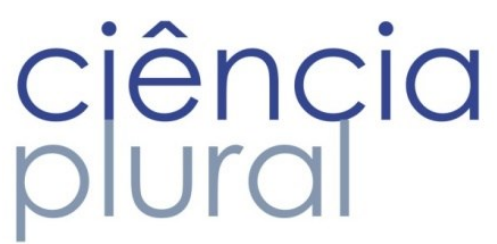

pensar e lidar com as enfermidades de ordem mentais, que passam a ser inseridas num processo contínuo de mudanças políticas, sociais e culturais, possibilitando o avanço para além das práticas manicomiais excludentes.

Entendemos que a autonomia é uma característica relativa a padrões individuais, sociais e históricos, estabelecidos ou construídos, e não um valor absoluto, implicando certo grau de dependência, modulando a capacidade do indivíduo de se organizar, podendo ser induzida ou facilitada por agentes externos. Desta forma, o exercício da autonomia está intimamente relacionado à totalidade do processo de vida dos sujeitos, refletindo o grau de auto-organização que entendemos estar nele presente. Consideramos, em suma, uma relação profunda entre "autonomia" e "auto-organização", onde o ganho de autonomia implica em melhores condições do indivíduo se auto-organizar, equilibrando-se em toda a dimensão de seu ser.

Enfim, se o resgate da autonomia já se coloca como horizonte tangível no tratamento de desarmonias mentais nos dias correntes (o que vai ao encontro da própria recomendação da OMS), entendemos que, ainda, falta um melhor entendimento teórico das inter-relações dos subsistemas que compõem o sistema humano em toda a sua complexidade, e que pensamos ser auto-organizado, onde a autonomia, exercitada pelas ações conscientes, seria de vital importância para a harmonia desse sistema extremamente dinâmico e complexo.

\section{Referências}

1. Organização Mundial da Saúde (OMS). Relatório sobre a saúde no mundo 2001: nova concepção, nova esperança. Brasília: Ministério da Saúde; 2001.

2. Descartes R. As paixões da alma. In: Discurso do método, meditações. objeções e respostas. Cartas. Tradução de J. Guinsburg e Bento Prado Júnior. São Paulo: Abril Cultural; 1973. p. 33-79. (Os Pensadores).

3. Descartes R. Meditações. In: Discurso do método. Meditações. Objeções e respostas. As paixões da alma. Cartas. Tradução de J. Guinsburg e Bento Prado Júnior. São Paulo: Abril Cultural; 1973. p 91-150. (Os Pensadores).

4. Mondolfo R. El pensamiento antiguo. Buenos Aires: Losada; 1942. 2v.

5. Koyré A. Introducción a la lectura de Platón. Madrid: Alianza Editorial; 1966. 


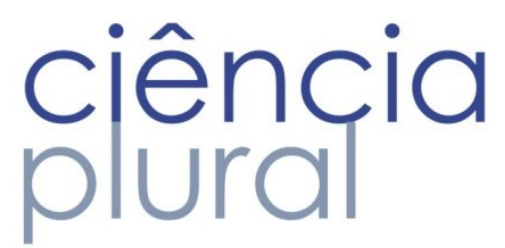

6. Bertalanffy LV. General system theory: foundations, development, applications. New York: George Braziller; 1968.

7. Asbhy WR. Principles of the self-organizing dynamic system. J Gen Psychol. 1947; 37(2):125-128.

8. Cournot AA. Des chances et des probabilités. Paris: Librairie de L. Hachette; 1843.

9. Debrun MA. A ideia de auto-organização. In: Debrun, ME. Q. Gonzales O, Pessoa Júnior, Editores. Auto-organização: estudos interdisciplinares. Campinas, SP: Unicamp; 1996. Coleção CLE. v. 18.

10. Debrun MA. Dinâmica da auto-organização primária. In: Debrun MM, Gonzalez MEQ, Pessoa Júnior O, organizadores. auto-organização: estudos interdisciplinares. Campinas: CLE/UNICAMP; 1996. p.25-59. (Coleção CLE.v. 18).

11. Von Foerster $\mathrm{H}$. On self-organizing systems and their environments. In: Yovits MC, Cameron S, Editores. self-organizing systems; 1960. p. 31-50.

12. Schrödinger E. What is Life? The physical aspect $f$ the living cell. Cambridge: Cambridge University Press; 1948.

13. Pereira Júnior A, Pereira MAO. Teoria da auto-organização: uma introdução e possível aplicação nas ciências da saúde. Rev Simbio-Logias. 2010; 3(5):102-114.

14. Maturana H, Varela F. Autopoiesis and cognition: The realization of the living. Boston: D. Reidel; 1980.

15. Aristóteles. Metafísica. Porto Alegre: Globo; 1969.

16. Chomsky N. Aspects of the Theory of Syntax. Cambridge: M.I.T. Press; 1965.

17. Lussi IAO, Freitas HI, Pereira Júnior A. Proposta teórica de um instrumento de auto avaliação em saúde mental. Cad Bras Ter Ocup. 2004; 12(1):5-14.

18. Turato ER. Métodos qualitativos e quantitativos na área da saúde: definições, diferenças e seus objetivos de pesquisa. Rev Saúde Pública. 2005; 39(3):507-14.

19. Rosana Onocko-Campos fala sobre estudos qualitativos como ferramenta de pesquisa no campo da Saúde Mental. 2013. Disponível em: https://www.abrasco.org.br/site/noticias/institucional/rosana-onockocampos-fala-sobre-estudos-qualitativos-como-ferramenta-de-pesquisa-no-campo-da-saude-mental/1311/. 


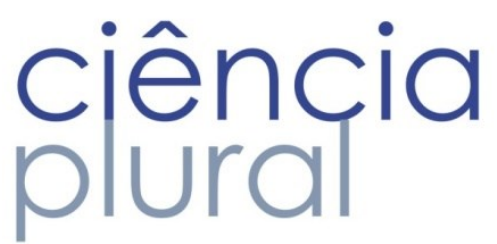

20. Junges M. Empoderamento dos usuários de saúde mental. Rev Instituto Humanitas. 2012; (391).

21. Saraceno B. Libertando identidades: da reabilitação psicossocial à cidadania possível. Rio de Janeiro: IFB/TeCorá; 1999.

22. Lussi IAO, Pereira MAO, Pereira Júnior A. A proposta de reabilitação psicossocial de Saraceno: um modelo de auto-organização? Rev Latino-Am Enfermagem. 2006; 14(3): 448-456.

23. Boarini ML. A Loucura no leito de procusto. Maringá: Dental Press; 2006.

24. Amarante P. Loucura, cultura e subjetividade: conceitos e estratégias, percursos e atores da reforma psiquiátrica brasileira. In: Fleury S, organizadora. Saúde e democracia: a luta do CEBES. São Paulo: Lemos Editorial; 1997. p.163-185.

25. Oliveira AGB, Alessi NP. Cidadania: instrumento e finalidade do processo de trabalho na reforma psiquiátrica. Ciênc Saúde Coletiva. 2005; 10(1): 191-203.

26. Morin E. A Noção de Sujeito. In: Schnitman DF, organizadora. Novos paradigmas, cultura e subjetividade. Porto Alegre: Artes Médicas; 1996. p. 45-56.

27. Canguilhem G. O Normal e o patológico. $4^{\mathrm{a}}$ ed. Rio de Janeiro: Forense Universitária; 1995.

28. Kinoshita RT. Contratualidade e reabilitação psicossocial. In: Pitta A, organizadora. Reabilitação psicossocial no Brasil. $2^{a}$ ed. São Paulo: Hucitec; 2001. p. 55-99.

29. Soares JCRS, Camargo Júnior KRA. A autonomia do paciente no processo terapêutico como valor para a saúde. Interface. 2007; 11(21):65-78.

30. Campos RTO, Campos GWS. Co-construção da autonomia: o sujeito em questão. Campos GWS, Carvalho YM, MInayo MCS, Drumond Junior M, Akerman M, organizadores. Tratado de Saúde Coletiva. São Paulo: Hucitec; 2006. 